\title{
Improvement Of Graves' Ophthalmopathy After Administration Of The Cyclooxygenase-2 Selective Inhibitor Celecoxib: A Case-Report
}

\author{
Adriana Gherbon \\ Deiana Roman \\ Romulus Timar \\ Second Department of Internal Medicine, "Victor Babes” University of \\ Medicine and Pharmacy, Timisoara, Romania \\ Clinic of Diabetes, Nutrition and Metabolic Diseases, Emergency Clinical \\ County Hospital, Timisoara, Romania \\ Mirela Frandes \\ Department of Functional Sciences, “Victor Babes” University of Medicine \\ and Pharmacy,Timisoara, Romania \\ Marioara Nicula \\ Banat's University of Agricultural Sciences and Veterinary Medicine "King \\ Michael I of Romania”, Timisoara, Romania \\ Doi:10.19044/esj.2021.v17n3p1 \\ Submitted: 30 October 2020 \\ Accepted: 08 January 2021 \\ Published: 31 January 2021 \\ Copyright 2021 Author(s) \\ Under Creative Commons BY-NC-ND \\ 4.0 OPEN ACCESS \\ Cite As: \\ Gherbon A., Roman D., Timar R., Frandes M. \& Nicula M. (2021). Improvement of Graves' \\ ophthalmopathy after administration of the Cyclooxygenase-2 Selective Inhibitor Celecoxib: \\ A case-report. European Scientific Journal, ESJ, 17(3), 1. \\ https://doi.org/10.19044/esj.2021.v17n3p1
}

\section{Abstract}

Graves' ophthalmopathy (GO) is a disabling complication of GravesBasedow disease, which in severe cases can progress toward blindness. Its treatment consists of the administration of corticosteroids, radiotherapy, as well as surgical treatment. The present report brings to your attention a case of moderate GO found in a patient recently diagnosed with Graves' disease that was resistant to the administration of Prednisone, stabilized under treatment with Celecoxib. A 45-year-old Caucasian woman presented in an outpatient facility with the following complaints: gritty feeling in both eyes, tachycardia, insomnia, anxiety, sweating, and weight loss. After the clinical 
examination and laboratory investigations, the patient has been diagnosed with Graves-Basedow disease and Graves' ophthalmopathy. Consecutively, treatment with Methimazole for Graves' disease and corticotherapy for Graves' ophthalmopathy were initiated. Due to the lack of response to Prednisone, other treatment methods were used, namely, Celecoxib $100 \mathrm{mg}$ treatment, twice per day for 8 weeks. Under treatment with Celecoxib, GO was stabilized and remained stable even after discontinuation, respectively at six months and one year after discontinuation. Celecoxib can be an alternative treatment for mild and moderate ophthalmopathy in newly diagnosed Graves’ disease.

Keywords: Graves-Basedow Disease, Ophthalmopathy, Celecoxib, Treatment

\section{Introduction}

Graves-Basedow disease is an autoimmune disease, the most common cause of thyrotoxicosis, with a 5-fold higher prevalence in female patient than in male ones. The maximum incidence of the disease can be observed between the second and fourth decade of life, but it can occur at any age. It can manifest through one or more of the following clinical aspects: thyrotoxicosis, ophthalmopathy, goiter, or dermopathy (in the form of pretibial myxedema) (Nikiforov et al, 2012).

Graves endocrine ophthalmopathy (GO) occurs in 20 - 40\% of patients with Graves-Basedow disease, and can appear either before thyrotoxicosis manifestations, concomitantly, or after the onset of the disease. It can be affect one or both eyes. The etiopathogenesis of orbitopathy is largely similar to that of Graves-Basedow disease, but its evolution may be independent to the evolution of Graves-Basedow disease. Its treatment consists of corticosteroids, radiotherapy, and surgical treatment. Due to the fact that, in some cases, patients do not respond or do not tolerate corticosteroid treatment, alternative treatments have been sought, namely, NSAIDs, biological therapy, etc. (Barrio-Barrio et al, 2015).

In this report, we bring to your attention a case of moderate GO in a patient with newly diagnosed Graves' disease, that had been stabilized under Celecoxib treatment.

\section{Main Text}

\section{Case presentation}

A 45-year-old Caucasian woman presented in an outpatient setting accusing a gritty feeling in both eyes, tachycardia, insomnia, anxiety, sweating, and weight loss. The patient had these symptoms for about one month. The patient's family history revealed high blood pressure (both parents), acute myocardial infarction, and the sudden death of the father, while 
the patient's medical history revealed no smoking or alcohol consumption, only high blood pressure for which treatment with ACE inhibitors and diuretics was administered. She did not present any history of thyroid disease. Previous blood tests had shown normal thyroid hormone and TSH levels and the absence of anti-thyroid antibodies. Over the last few months, the patient had been in a stressful environment both at work and at home.

At the initial examination, the patient weighed $58 \mathrm{~kg}$, at a height of $1.55 \mathrm{~m}$, having a BMI of $24.16 \mathrm{~kg} / \mathrm{m}^{2}$. She presented clinical signs of hyperthyroidism: tachycardia, insomnia, anxiety, sweating, and weight loss. The results of the physical examination included good general status, edema of the eyelids, no abnormalities regarding the respiratory system, regarding the cardiovascular cardio-vascular system the patient had regular sinus rhythm, tachycardia (HR $=108 \mathrm{~b} / \mathrm{min}$ ), $\mathrm{BP}=130 / 80 \mathrm{mmHg}$ (under treatment with diuretics and ACE inhibitors), the patient' digestive and genitourinary tract were normal, there were no signs of meningeal irritation, reflexes were normal, the thyroid was impalpable, without goiter. Because the patient presented with a gritty sensation in both eyes, an ophthalmological consultation was also performed, ex-ophthalmometry revealing the presence of GO, with a value of $19 \mathrm{~mm}$ for the right eye, respectively, $18 \mathrm{~mm}$ for the left eye, with a base of $110 \mathrm{~mm}$. In addition to measuring proptosis $(\mathrm{mm})$ using the ex-ophthalmometer, the presence or absence of ocular misalignment in prism diopters, eyelid retraction, visual acuity and visual field were also determined. No changes were found in the latter. Thyroid Eye Disease Clinical Activity Score was also calculated, with a value of 4, indicating mild impairment.

Cerebral CT examination revealed no expansive intracerebral formations above or below the tentorium on either side. Median structures were in normal position and normal-sized symmetrical ventricular system. The orbits, the base of the skull, and the craniofacial sinuses were normal in appearance.

Ocular CT examination revealed that she presented symmetrical eyeballs, with an exophthalmic index of $15 \mathrm{~mm}$, and homogeneous extraocular orbital content.

The palpatory examination of the thyroid showed a normal volume, without the presence of goiter. Thyroid ultrasound examination revealed a homogeneous, hypoechogenic structure with a volume of $3.7 \mathrm{ml}$ for the right lobe, respectively $2.7 \mathrm{ml}$ for the left lobe, and a thyroid isthmus of $4.3 \mathrm{~mm}$. Laboratory investigations identified the presence of overt clinical hyperthyroidism, with decreased TSH and increased thyroid hormones, negative anti-thyroid antibodies, but positive anti-TSH receptor antibodies (Table 1). 
Table 1. The hormonal and antibodies profile and exophthalmometry.

\begin{tabular}{|c|c|c|c|c|c|c|}
\hline & T0 & T1 & T2 & T3 & T4 & T5 \\
\hline $\mathrm{FT}_{3}(\mathrm{pg} / \mathrm{ml})$ & 9.09 & 3.81 & 3.04 & 3.68 & 2.48 & 2.72 \\
\hline $\mathrm{FT}_{4}(\mathrm{ng} / \mathrm{dl})$ & 3.03 & 1.77 & 1.3 & 1.51 & 1.16 & 1.12 \\
\hline $\mathrm{TSH}(\mu \mathrm{UI} / \mathrm{ml})$ & $<0.001$ & $\mathrm{NA}$ & $\begin{array}{c}< \\
0.016\end{array}$ & NA & NA & NA \\
\hline $\mathrm{AB}$ antiTPO (UI/ml) & 26.6 & NA & NA & NA & NA & NA \\
\hline AB antiTG (UI/ml) & 18.9 & NA & NA & NA & NA & NA \\
\hline $\begin{array}{c}\text { AB antireceptor TSH } \\
(\mathrm{UI} / \mathrm{L})\end{array}$ & 5.38 & NA & NA & NA & NA & NA \\
\hline Ex-ophthalmometry (mm) & & & & & & \\
\hline Right eye & 19 & 18 & 18 & 20 & 22 & 22 \\
\hline Left eye & 18 & 18 & 18 & 19 & 21 & 23 \\
\hline
\end{tabular}

Notes: Normal values - FT3 (pg/ml): 2.3 to 4.2; FT4 (ng/dl): 0.89 to 1.76; TSH (mUI/ml): 0.55 to 4.78; $\mathrm{AB}$ antiTPO (UI/ml): $<35$; AB antiTG (UI/ml): $<60$.

Abbreviations: $\mathrm{AB}$ antiTG=antithyroglobulin antibodies, $\mathrm{AB}$ antiTPO=antithyroid peroxidase antibodies, $\mathrm{AB}$ anti-receptor $\mathrm{TSH}=$ anti-receptor $\mathrm{TSH}$ antibodies, $\mathrm{FT}_{3}=$ free triiodothyronine, $\mathrm{FT}_{4}=$ free thyroxine, $\mathrm{TSH}=$ thyroid stimulating hormone.

Treatment was initiated on day two of admission consisting in $15 \mathrm{mg}$ of Prednisone per day for 3 weeks and Methimazole $15 \mathrm{mg}$ per day, Selenium $200 \mu \mathrm{g} / \mathrm{day}$, and topical corticotherapy with Dexamethasone. Consecutively, an improvement could be observed through improvement of exophthalmometry, both eyes were at $18 \mathrm{~mm}$ proptosis. After three weeks, $\mathrm{FT}_{3}$ was $3.81 \mathrm{pg} / \mathrm{ml}$ and $\mathrm{FT}_{4} 1.77 \mathrm{ng} / \mathrm{dl}$. Treatment with Prednisone was reduced to $5 \mathrm{mg} /$ week and the administration of Methimazole remained at a dosage of $15 \mathrm{mg} /$ day. After another three weeks, the level of $\mathrm{FT}_{4}$ was $1.3 \mathrm{ng} / \mathrm{ml}$, that of $\mathrm{FT}_{3}$ was $3.04 \mathrm{pg} / \mathrm{ml}$, and that of the TSH was $0,016 \mathrm{mUI} / \mathrm{ml}$. At the same time, ex-ophthalmometry showed that both eyes were stable at $18 \mathrm{~mm}$. The treatment with Prednisone was interrupted and the Methimazole dose was reduced to $10 \mathrm{mg} /$ day. After one month, the $\mathrm{FT}_{3}$ was $3.68 \mathrm{pg} / \mathrm{ml}$ and $\mathrm{FT}_{4} 1.51$ $\mathrm{ng} / \mathrm{ml}$, although after ex-ophthalmometry, the right eye presented an increase to $20 \mathrm{~mm}$, and the left eye an increase to $19 \mathrm{~mm}$. The oral Prednisone treatment was resumed and the Methimazole dose was further reduced to $5 \mathrm{mg} / \mathrm{day}$. After one week, the ex-ophthalmometry revealed that the left eye was $22 \mathrm{~mm}$ and the right eye was $21 \mathrm{~mm}$. Pulse therapy was initiated, using Prednisone for 3 days, then oral Prednisone treatment with $32 \mathrm{mg} /$ day for 3 days, which was afterward reduced to using $8 \mathrm{mg} /$ day for three days per week, with maintained dosage. Additionally, local treatment with Dexamethasone was initiated. Three weeks later, the $\mathrm{FT}_{3}$ level was $2.48 \mathrm{pg} / \mathrm{ml}$ and $\mathrm{FT}_{4}$ was 1.16 $\mathrm{ng} / \mathrm{dl}$. The Methimazole treatment was halted and due to the increase of both intraocular and blood pressure, Dexamethasone use was discontinued and the oral corticotherapy was reduced to $4 \mathrm{mg} /$ day. After an additional period of three weeks, $\mathrm{FT}_{3}$ was $2.72 \mathrm{pg} / \mathrm{ml}, \mathrm{FT}_{4}$ levels were $1.12 \mathrm{ng} / \mathrm{dl}$, and ex- 
ophthalmometry revealed that the left eye was at $23 \mathrm{~mm}$ and the right eye at $22 \mathrm{~mm}$. Pulse therapy with Prednisone was reintroduced, then oral treatment with a dose of $32 \mathrm{mg} /$ day, as well as local treatment with Dexamethasone.

Due to the lack of adequate response to Prednisone and increased blood pressure and intraocular pressure, new alternatives for management were considered. In literature, there are studies regarding the high Cox-2 expression in T-lymphocytes which can play a proinflammatory role in the condition, that were not being targeted by Prednisone. Therefore, the patient was gradually taken off Prednisone and began treatment with $100 \mathrm{mg}$ of Celecoxib twice daily for 3 weeks. Under Celecoxib treatment, the patient's ex-ophthalmometry improved in the right eye to $21 \mathrm{~mm}$ and remained the same in the left eye. The patient continued treatment with $100 \mathrm{mg}$ of Celecoxib twice daily for a total of 8 weeks. The dosage was then reduced to $100 \mathrm{mg} / \mathrm{day}$ for one week and then discontinued because of medication-induced epigastric pain and hypertension.

During those three months, the thyroid function remained normal: $\mathrm{FT}_{3}$ at 3.36 $\mathrm{pg} / \mathrm{ml}, \mathrm{FT}_{4}$ at $1.43 \mathrm{ng} / \mathrm{ml}$ in the first month, $\mathrm{FT}_{3}$ at $3.25 \mathrm{pg} / \mathrm{ml}, \mathrm{FT}_{4}$ at $1.61 \mathrm{ng} / \mathrm{ml}$ in the second month, and $\mathrm{FT}_{3}$ at $3.04 \mathrm{pg} / \mathrm{ml}$, and $\mathrm{FT}_{4}$ at $1.31 \mathrm{ng} / \mathrm{dl}$ in the third month. One month after discontinuation, the ex-ophthalmometry showed 21 $\mathrm{mm}$ in both eyes, $\mathrm{FT}_{3}=3.74 \mathrm{pg} / \mathrm{ml} \mathrm{FT}_{4}=1.23 \mathrm{ng} / \mathrm{ml}, \mathrm{TSH}=3.238 \mu \mathrm{UI} / \mathrm{ml}$, and anti-receptor $\mathrm{TSH} \mathrm{AB}=0.64 \mathrm{UI} / \mathrm{l}$. At the next evaluation, the exophthalmometry showed $21 \mathrm{~mm}$ at both eyes and the $\mathrm{FT}_{3}$ was $3.74 \mathrm{pg} / \mathrm{ml} \mathrm{FT}_{4}$ was $1.17 \mathrm{ng} / \mathrm{l}$, TSH was $1.92 \mu \mathrm{UI} / \mathrm{ml}$ and anti-receptor TSH AB was $1.31 \mathrm{UI} / \mathrm{l}$ (Table 2).

Table 2. The hormonal and antibodies profile and ex-ophthalmometry and follow-up

\begin{tabular}{|c|c|c|c|c|c|}
\hline & T1 & T2 & T3 & T4 & T5 \\
\hline $\mathrm{FT}_{3}(\mathrm{pg} / \mathrm{ml})$ & 3.36 & 3.25 & 3.04 & 3.74 & 3.74 \\
\hline $\mathrm{FT}_{4}(\mathrm{ng} / \mathrm{dl})$ & 1.43 & 1.61 & 1.31 & 1.23 & 1.17 \\
\hline $\mathrm{TSH}(\mu \mathrm{UI} / \mathrm{ml})$ & NA & NA & NA & 3.238 & 1.92 \\
\hline $\mathrm{AB}$ antiTPO $(\mathrm{UI} / \mathrm{ml})$ & 24.4 & NA & NA & NA & NA \\
\hline $\mathrm{AB}$ antiTG $(\mathrm{UI} / \mathrm{ml})$ & 16.9 & NA & NA & NA & NA \\
\hline AB antireceptor TSH & NA & NA & 0.64 & NA & 1.31 \\
\hline $\begin{array}{c}\text { Ex-ophthalmometry } \\
(m m)\end{array}$ & & & & & \\
\hline Right eye & 21 & NA & NA & 21 & 21 \\
\hline Left eye & 21 & NA & NA & 21 & 21 \\
\hline
\end{tabular}

Notes: Normal values - FT3 (pg/ml): 2.3 to 4.2; FT4 (ng/dl): 0.89 to 1.76; TSH (mUI/ml): 0.55 to 4.78 ;

Abbreviations: FT3=free triiodothyronine, FT4=free thyroxine, T1=measurements after 1 month, T2=measurements after 2 months, T3=measurements after 3 months,

T4=measurements after 6 months, T5=measurements after 1 year, TSH=thyroid stimulating hormone. 
Laboratory investigations showed normal thyroid function and stabilized ophthalmopathy at 1, 2, 3, 6, and 12 months after the end of treatment with Celecoxib. Because the patient was young, the remission of Graves' disease was obtained, with the stabilization of ophthalmopathy at a value of $21 \mathrm{~mm}$ bilaterally. Subsequently, thyroid function and exophthalmometry were monitored every 3 months with maintaining Graves' disease remission and stabilized ophthalmopathy.

\section{Discussion}

We reported a case of moderate ophthalmopathy in relation to a newly diagnosed case of Graves' disease that was stabilized under treatment with Celecoxib.

Graves-Basedow disease is an autoimmune disease triggered by certain viral or bacterial infections (e.g., Yersinia enterocolitica), psychological stress, smoking, estrogen and postpartum period, excessive administration of iodine (especially in iodine deficient areas) or of drugs certain drugs such as Amiodarone (Gherbon et al, 2019). The manifestations of the disease include thyrotoxicosis, ophthalmopathy, goiter, dermopathy (pretibial myxedema).

GO is an autoimmune disorder in which the immune system attacks orbital tissues, determinate changes in eyelid position, globe position in the orbit, extraocular muscle balance, and optic nerve function. The characteristic of this disease is an inflammation of the idiopathic lymphocytic orbital accompanied by autoimmune activation of orbital fibroblasts. The activation is expressed by the TSH receptor (Shan et al, 2014). The etiopathogenesis of orbitopathy is largely similar to that of Graves-Basedow disease. Initial activation of $\mathrm{T}$ cells in Graves orbitopathy is determined by the presence of the TSH receptor antigen in fibroblasts and adipocytes of the retrobulbar tissue. TSH-R also plays an important role in GO. There is hypertrophy of the extrinsic and intrinsic ocular muscles, but also the increase in the volume of the retrobulbar adipose tissue by inflammation and accumulation of hydrophilic glycosaminoglycans (GAGs), mainly hyaluronic acid. GAGs are secreted by fibroblasts following the action of cytokines (TNF $\alpha$, interferon $\gamma$ ) secreted at the level of activated $\mathrm{T}$ cells, causing changes in intra-orbital osmotic pressure, followed by fluid accumulation and protrusion of the eyeballs (Shan et al, 2014). In time, it can lead to dysthyroid optic neurophathy, increased intraocular pressure or proptosis (Tan et al, 2017).

The management of patients with GO depends on the impact of the disease on the patient's quality of life and the risk of vision loss. For all patients with GO, the initial measurement consists of controlling risk factors for progression (smoking and thyroid dysfunction), and of topical measures (artificial tears, ointments and dark glasses) (Bartalena et al, 2016). In mild 
forms of GO, the treatment consists of a watchful strategy and a 6-month course of Selenium supplementation (Marcocci et al, 2011). In moderate-tosevere forms of GO, high-dose glucocorticoids (GCs) are recommended, preferably administered via the intravenous route as the first line-treatment for nonspecific reduction of inflammation (Zang et al, 2011). The second-line treatment consists of a second course of intravenous GCs, oral GCs combined with orbital radiotherapy or cyclosporine, rituximab or watchful waiting (Salvi et al, 2015). In some cases, it is needed a rehabilitative treatment (orbital decompression surgery, squint surgery or eyelid surgery) because of the progression of GO from the inflammatory phase to fibrotic, resolution phase, when the orbital changes become fixed and can be modified only by surgery (Eckstein et al, 2015).

The initial treatment for our patient consisted of Prednisone, though due to the lack of response, new alternatives of management were considered. Given that a decrease of inflammation is achieved only with the support of corticotherapy or radiotherapy (which the patient refused) in Romania since other drugs such as cyclosporine and rituximab are not approved for the treatment of GO, other therapeutic measures had to be considered.

In literature, there are reports of the treatment of GO with Cox-2 inhibitors. Specific to GO T-lymphocyte infiltration of the extraocular muscle tissue and orbital fatty connective tissue and T-lymphocyte activation increased expression of Cox-2 are encountered. Via Cox-2, T-lymphocytes can synthesize certain prostaglandins and interleukin-8 (IL-8), determine the dysregulation of Cox-2 expression by T-cells in GO and increase Tlymphocyte survival in GO (Feldon et al, 2005). Some in-vitro studies showed that T-lymphocyte-driven orbital fibroblast adipogenesis is inhibited by blocked Cox-2 activity (Kuryan et al, 2013). The TSH receptor and/or insulinlike growth factor-1 receptor are involved in the T-lymphocyte activation (Douglas et al, 2011).

In vitro studies showed positive results in the reduction of inflammation in GO using COX-2 inhibitors (Cheng et al, 2016), so we chose to administer a COX-2 inhibitor in the formulation of Celecoxib $100 \mathrm{mg}$, twice daily for 3 weeks. Celecoxib is a non-steroidal anti-inflammatory drug approved for the pain management, as well as for some autoimmune diseases such as rheumatoid arthritis, and ankylosing spondylitis (Gong et al, 2012). The side effects of this drug are abdominal pain, nausea, diarrhea, but also heart attacks, strokes, gastrointestinal perforation, gastrointestinal bleeding, kidney failure, and anaphylaxis (Bhala et al, 2013). In vitro data have shown that the transformation of orbital fibroblasts into adipocytes is mediated by cyclooxygenase-2 (COX-2), and a case report suggests that COX-2 inhibition can improve GO in the acute phase (Kuryan et al, 2008). 
Unfortunately, there are not many studies regarding the effect of Celecoxib on GO. The latest study was conducted by Johns Hopkins University and included 7 participants, of which 6 with GO and 1 control. The investigators attempted to treat a cohort of patients with active TED using a selective COX-2 inhibitor, Celecoxib, and to compare these patients to an observational control group. The investigators hypothesized that Celecoxib will reduce the severity of disease and/or prevent progression to proptosis, diplopia, and corneal exposure or compressive optic neuropathy. The investigators would enroll patients with active TED and treat them for 3 months (a characteristic period of disease activity) and compare this to standard treatments for mild active TED (observation, with over the counter interventions such as lubrication with artificial tears) to assess efficacy. Unfortunately, only one patient remained to be followed in the study, in which it was observed that under the treatment with Celecoxib the parameters followed did not modify (John Hopkins University, 2020).

Our patient presented a good response to Celecoxib in regard to their symptoms. The patient continued treatment with $100 \mathrm{mg}$ of Celecoxib twice per day for a total of 8 weeks. The dosage was then reduced to $100 \mathrm{mg} / \mathrm{day}$ for one week and then discontinued because of medication-induced side effects such as epigastric pain and hypertension. Although we cannot exclude spontaneous remittance or delayed response to initial treatment, the prompt response to Celecoxib suggests that the in vitro findings of Cox-2-dependent inflammatory pathways may be active in vivo.

The patient's quality of life improved due to the finding of an alternative treatment to corticotherapy that rendered the desired results, stabilizing Graves' ophthalmopathy.

\section{Conclusion}

Administration of Celecoxib, a Cox-2 inhibitor, with an antiinflammatory role, demonstrates that this medication inhibits the inflammatory phase of GO, and stabilizes this disease in the acute phase. Based upon our results and the response of our patient to the selective Cox-2 inhibitor celecoxib, this can be an alternative treatment for mild and moderate ophthalmopathy in newly diagnosed Graves' disease.
Abbreviations
GO = Graves endocrine ophthalmopathy;
$\mathrm{TSH}=$ thyroid stimulating hormone;
$\mathrm{CT}$ = computer tomography;
$\mathrm{AB}$ antiTG = antithyroglobulin antibodies;
$\mathrm{AB}$ antiTPO = antithyroid peroxidase antibodies;
$\mathrm{AB}$ anti-receptor TSH = anti-receptor TSH antibodies; 
$\mathrm{FT}_{3}=$ free triiodothyronine;

$\mathrm{FT}_{4}=$ free thyroxine;

$\mathrm{T} 1$ = measurements after 1 month;

$\mathrm{T} 2$ = measurements after 2 months;

$\mathrm{T} 3$ = measurements after 3 months;

$\mathrm{T} 4$ = measurements after 6 months;

$\mathrm{T} 5$ = measurements after 1 year;

TSH-R = TSH receptor;

GCs $=$ high-dose glucocorticoids.

\section{Declarations}

\section{Ethics approval and consent to participate}

This case-report was approved by the Ethics Committee of the University Emergency Clinical Hospital "Pius Brinzeu" Timisoara, Romania. The ethical approval number is 199-C1/2020.

\section{Consent for publication}

Written informed consent was obtained from the patient.

\section{Availability of data and materials}

The datasets of this study are available from the corresponding author on reasonable request.

\section{Competing interests}

The authors declare that they have no competing interests.

\section{Funding}

No funding was obtained for this study.

\section{Authors' contributions}

AG designed the case-report. MF contributed to the literature research and preparation of the manuscript and tables. DR, MN and RT contributed to the writing of the manuscript. All authors read and approved the final manuscript.

Acknowledgments: We thank the patient for her participation in this study. 


\section{References:}

1. Barrio-Barrio, J., Sabater, A.L., Bonet-Farriol, E., Velasquez-Villoria, A., Galofre, J.C. (2015). Graves' ophthalmopathy: VISA versus EUGOGO classification, assessment, and management. J Ophthalmol, 249125.

2. Bartalena, L., Baldeschi, L., Boboridis, K., Eckstein, A., Kahaly, G.J., Marcocci, C., Perros, P., Salvi, M., Wiersinga, W.M. and European Group on Graves" Orbitopathy (EUGOGO).(2016). The 2016 European Thyroid Association/European Group on Graves' Orbitopathy Guidelines for the Management of Graves' Orbitopathy. Eur Thyroid J. 5:9-26.

3. Bhala, N., Emberson, J., Merhi, A., Abramson, S., Arber, N., Baron, J.A., Bombardier, C., Cannon, C., Farkouh, M.E., FitzGerald, G.A., Goss, P., Halls, H., Hawk, E., Hawkey, C., Hennekens, C., Hochberg, M., Holland, L.E., Kearney, P.M., Laine, L., Lanas, A., Lance, P., Laupacis, A., Oates, J., Patrono, C., Schnitzer, T.J., Solomon, S., Tugwell, P., Wilson, K., Wittes, J., Baigent, C. (2013). Vascular and upper gastrointestinal effects of non-steroidal anti-inflammatory drugs: meta-analyses of individual participant data from randomized trials. Lancet. 382(9894):769-79.

4. Cheng, A.M.S., Yin, H.Y., Chen, A., Liu, Y.W., Chuang, M.C., He, H., Tighe, S., Sheha, H., Liao, S-L. (2016). Celecoxib and Pioglitazone as Potential Therapeutics for Regulating TGF- $\beta$-Induced Hyaluronan in Dysthyroid Myopathy. Invest. Ophthalmol. Vis. Sci. 57(4):19511959.

5. Douglas, R.S. and Gupta, S. (2011). The pathophysiology of thyroid eye disease: implications for immunotherapy. Curr Opin Ophthalmol. 22:385-390.

6. Eckstein, A., Esser, J. (2015). Surgical management of extraocular muscle dysfunction in patients with GO; in Bahn RS (ed): Graves' Disease. New York, Springer, pp 287-299.

7. Feldon, S.E., Park, D.J., O'Loughlin, C.W., Nguyen, V.T., Landskroner-Eiger, S., Chang, D., Thatcher, T.H., Phipps, R.P. (2005). Autologous T-lymphocytes stimulate proliferation of orbital fibroblasts derived from patients with Graves’ ophthalmopathy. Invest Ophthalmol Vis Sci. 46:3913-21.

8. Gherbon, A., Frandes, M., Lungeanu, D., Nicula, M., Timar, R. (2019). Transient Hyperthyroidism following the ingestion of complementary medications containing kelp seaweed. Medicine. 98:37(e17058).

9. Gong, L., Thorn, C.F., Bertagnolli, M.M., Grosser, T., Altman, R.B., Klein, T.E. (2012). Celecoxib pathways: pharmacokinetics and pharmacodynamics. Pharmacogenet Genomics. 22(4):310-318. 
10. John Hopkins University. (2020) Celecoxib for Thyroid Eye Disease. ClinicalTrials.gov. NTC02845336

11. Kuriyan, A.E., Woeller, C.F., O'Loughlin, C.W., Phipps, R.P., Feldon, S.E. (2013). Orbital Fibroblasts From Thyroid Eye Disease Patients Differ in Proliferative and Adipogenic Responses Depending on Disease Subtype. Invest. Ophthalmol. Vis. Sci. 54(12):7370-7377.

12. Kuryan, A.E., O'Loughlin, C.W., Phipps, R., Feldon, S.E. (2008). Improvement of Thyroid Eye Disease Following Treatment with the Cyclooxygenase-2 Selective Inhibitor Celecoxib. Thyroid. 18(8):9114.

13. Marcocci, C., Kahaly, G.J., Krassas, G.E., Bartalena, L., Prummel, M., Stahl, M., Altea, M.A., Nardi, M., Pitz, S., Boboridis, K., Sivelli, P., von Arx, G., Mourits, M.P., Baldeschi, L., Bencivelli, W., Wiersinga, W., European Group on Graves Orbithopathy. (2011). Selenium and the course of mild Graves' orbitopathy. N Engl J Med. 364:1920-1931.

14. Nikiforov, Y.E., Biddinger, P.W., Nikiforova, L.D., Biddinger, P.W. (2012). Diagnostic pathology and molecular genetics of the thyroid (2nd ed.). Philadelphia: Wolters Kluwer Health/Lippincott Williams \& Wilkins, p. 69.

15. Salvi, M., Vannucchi, G., Curro, N., Campi, I., Covelli, D., Dazzi, D., Simonetta, S., Guastella, C., Pignataro, L., Avignone, S., Beck-Peccoz, P. (2015). Efficacy of B-cell targeted therapy with rituximab in patients with active moderate to severe Graves' orbitopathy: a randomized controlled study. J Clin Endocrinol Metab. 100:422-431.

16. Shan, S.J., Douglas, R.S.(2014). The pathophysiology of thyroid eye disease. Journal of Neuro-Ophthalmology. 34 (2):177-85.

17. Tan, N.Y., Leong, Y.Y., Lang, S.S., Htoon, Z.M., Young, S.M., Sundar, G. (2017). Radiologic Parameters of Orbital Bone Remodeling in Thyroid Eye Disease. Investigative Ophthalmology \& Visual Science. 58 (5):2527-2533.

18. Zang, S., Ponto, K.A., Kahaly, G.J. (2011). Clinical review: intravenous glucocorticoids for Graves' orbitopathy: efficacy and morbidity. J Clin Endocrinol Metab. 96:320-332. 